\title{
Insights Into the Etiology of Gummosis Syndrome of Deciduous Fruit Trees in Israel and its Impact on Tree Productivity
}

David Ezra, Michal Hershcovich, and Dani Shtienberg, Department of Plant Pathology and Weed Research, Agricultural Research Organization, the Volcani Center; Reshon LeZion, 7528809 Israel

\begin{abstract}
Fungal gummosis syndrome of deciduous fruit trees was reported from several countries, including Israel. Symptomatic 5-7 to 10-14-year-old trees exude large amounts of gum on the trunk, limbs, branches, and twigs, accompanied by sunken lesions on the bark. The necrotic area extends to the xylem to form black to brown staining of the tissue. The general conception is that "this is a nuisance that can be pruned out of trees during the dormant season with no economic significance." In this study we attempted to: (i) identify the fungi associated in the gummosis syndrome of deciduous trees in Israel and (ii) quantify the significance of gummosis syndrome on tree and fruit development and on crop value. Branches from symptomatic and asymptomatic deciduous trees were collected during 2012 to 2015 from 29 orchards including peach (14 orchards), nectarine (six orchards), apricot (six orchards), plum, cherry,

and almond (one orchard each). In all cases, fungi associated with the Botryosphaeriaceae family were isolated from tissues exhibiting the typical gummosis symptoms. The decay fungus Phellinus sp. was isolated from $53.3 \%$ of the samples. The dynamics of fruit growth in symptomatic and asymptomatic trees was recorded in 2014 and 2015 in an 11-year-old peach orchard. In trees exhibiting the gummosis syndrome, yield was lower by 11.5 to $22.5 \%$ and its value was reduced by 14.7 to $19.4 \%$, compared with those of asymptomatic trees in 2014 and 2015, respectively. Although these are substantial losses, the grower of the orchard was not aware of the losses occurring in his orchard. The reason for this situation is explained and discussed. The outcome conclusion of the current study is that the gummosis syndrome of deciduous trees imposes significant, hence undistinguishable, losses in mature deciduous fruit trees.
\end{abstract}

Fungal gummosis syndrome of deciduous fruit trees was described in the United States and Japan in the 1960s (Ogawa et al. 1995). Since then, it was reported from other countries such as China, Australia (Ogawa et al. 1995), Uruguay (Sessa et al. 2016), South Africa, and more (Slippers et al. 2007). Symptomatic trees exude large amounts of gum on the trunk, limbs, branches, and twigs, accompanied by sunken lesions on the bark. The necrotic area extends to the xylem to form black to brown staining of the tissue (Li et al. 1995). At later stages, twigs, branches, shoots, and limbs wilt and die (Beckman et al. 2003). On some infected shoots or dead wood, a production of black stroma can be found (Li et al. 1995; Ogawa et al. 1995).

Fungal gummosis syndrome of deciduous fruit trees is caused by multiple fungi; some belong to the genus Botryosphaeria and others are wood decay fungi. Nattrass (1933) reported that Hendersonula sp. (syn. Neoscytalidium sp.) was the causal agent of gummosis syndrome on apples, plum, and apricot in Egypt. During the 1960s, the disease was described in the United States and Japan and Botryosphaeria dothidea was isolated from symptomatic trees (Ogawa et al. 1995; Weaver 1974). Lasiodiplodia theobromae has been reported as the causal agent of gummosis syndrome in Japanese apricot and peach in China and South Africa (Damm et al. 2007; Li et al. $1995,2014)$. The presence of wood decay fungi in association with the syndrome has been also described on peach (Adaskaveg et al. 1993) and nectarine in the U.S.A. and Canada (Chen et al. 2015). Wood decay fungi are usually found on pruning wounds. Nevertheless, once they establish in the wood, they affect the long term health and survival of the tree. These fungi not only use the tree's resources, but the decay process weakens limbs and reduces their ability to bear load (Chen et al. 2015).

Corresponding author: David Ezra; E-mail: dezra@ volcani.agri.gov.il

Accepted for publication 6 April 2017.

C) 2017 The American Phytopathological Society
The effect of fungal gummosis syndrome of deciduous fruit trees on the yield is not well documented (Beckman et al. 2003). In the U.S.A., it is considered as "a nuisance that can be pruned out of trees during the dormant season with no economic significance" (Beckman et al. 2003). In China, Li et al. (1995) reported that disease incidence in the area around Zhejiang ranged from 46 to $100 \%$ and mentioned that the syndrome reduced fruit production. Attempts to cope with gummosis syndrome reveled that frequent scraping of the lesions and painting of the exposed tissue with chemicals inhibit the pathogens in the trees and suppress the disease, but their economic benefit was questionable (Beckman et al. 2003; Li et al. 1995)

In Israel, the fungal gummosis syndrome was studied by Sztejnberg and colleagues during the late 1970s. Based on a countrywide survey, the main causal agent was identified as Hendersonula toruloidea Nattrass (Achilea and Sztejnberg 1976; Jakoby et al. 1982; Rotem et al. 1991). In recent years, the syndrome is frequently observed in various deciduous fruit species including plum, peach, apricot, nectarine, cherry, and almond. The causal agent is not known in most cases but the symptoms are very similar to those described above. In respect to gummosis syndrome, the timespan of deciduous plantations can be divided into four phases. The first extends from planting to 2 to 3 years after panting. During that time, the symptomatic (young) trees are scattered randomly in the orchard. On these trees, abundant gum secretion is observed on the lower parts of the trunks and most of the symptomatic trees will eventually wilt and die. The second phase extends from 2-3 years to 5-7 years after planting. During that time, the trees establish, grow, bear fruits, and flourish. In most cases, the trees are symptomless and are considered healthy. The third phase extends from 5-7 to 10-14 years after planting. During that time, gum secretion is resumed and can be observed on branches, limbs, and trunks of sporadic trees in the orchard. At the same time, occasional wilting and death of side shoots and branches is recognized. Furthermore, the normal growth and development of affected trees is impaired and the canopy of symptomatic trees is less dense than that of nearby asymptomatic trees. In most cases, restricted growth and shoot dieback occur on trees that secrete gum. Growers cut and remove the wilting shoots and branches, thus, 
the orchard maintains its "healthy" appearance. As deciduous fruit trees flower abundantly, growers usually thin the surplus flowers in an attempt to adjust the number of developing fruits to the tree's capability. Accordingly, the number of fruits developing on symptomatic trees (those with gum secretion, restricted growth, and shoot dieback) is comparable to the number of fruits developing on asymptomatic, presumably healthy trees. As growers do not weight fruits from individual trees, the conception is that yield is not lessened during this phase. The fourth phase of gummosis syndrome development in the timespan of deciduous plantations lasts from 10-14 years to 15-20 years after planting. During that phase, gum secretion from the main limbs and trunks is intensified and drying and wilting of main limbs and entire trees become widespread in the orchard. Yield is significantly reduced and the profitability of production is evidently diminished. Eventually, the growers decide to uproot the infected orchard to minimize their losses. The outcome is that the lifespan of deciduous fruit trees in Israel is 15 to 20 years.

The current report focuses on the third phase of the gummosis syndrome of deciduous trees. It is not known which pathogens are associated with the syndrome in Israel, the source of initial inoculum, or when they invaded the trees. In that regard, our research hypothesis is that the syndrome results from a complex of multiple fungi that attack the trees mutually. As indicated above, the common belief is that yield of symptomatic trees is not impaired. In that regard, our research hypothesis is that the weight of fruits developing on symptomatic trees in the third phase of the gummosis syndrome, and their value, are inferior to the weight of fruits growing on nearby asymptomatic trees. The specific objectives of the present study were: (i) to identify the fungi associated in the gummosis syndrome of deciduous trees in Israel, and (ii) to quantify the significance of gummosis syndrome on tree and fruit development and on crop value of peach.

\section{Materials and Methods}

The fungi associated with the gummosis syndrome of deciduous trees in Israel. Branches from symptomatic and asymptomatic deciduous trees were randomly collected during the spring and summer of 2012 to 2015. Samples were taken from all deciduous fruit tree production areas in the country, from the far north (Yesud HaMa'ala) to the south (Neot Semadar). Samples were taken from 29 orchards including peach (14 orchards), nectarine (six orchards), apricot (six orchards), plum, cherry, and almond (one orchard each). From each orchard, branches, about $50 \mathrm{~cm}$ in length, were cut from different trees and brought to the laboratory in the Volcani center. In some cases, cores were drilled out from the trunks of the trees using a $4.3 \mathrm{~mm}$ Haglof3-thread increment borer (Haglof, Sweden). To ensure isolation of microorganisms only from the internal part of the wood, the samples' surfaces were disinfected: the branches were cut into $2 \mathrm{~cm}$ thick slices that were dipped in $1 \%$ hyper chloride solution (final concentration) for $3 \mathrm{~min}$ followed by two $5 \mathrm{~min}$ rinses in distilled water. Each slice was cut to $0.5 \mathrm{~cm}$ vertical $(2$ to $3 \mathrm{~cm}$ from the edge) and the two inner cuts were cut to small $0.5 \times 0.5 \mathrm{~cm}$ pieces. The small pieces were then placed on $0.25 \%$ potato dextrose agar media (PDA; Acomedia, U.S.A.), five pieces per Petri dish (90 mm), and incubated at $25^{\circ} \mathrm{C}$ in the dark for about 7 days during which fungal growth was monitored. Whenever fungal growth was detected, a plug of agar with mycelia was transferred to a new PDA plate and let to grow for 5 to 7 days before it was evaluated for morphological and microscopic identification. Fungal cultures that were morphologically identified as associated with the Botryosphaeriaceae family or Phellinus spp. were used to obtain single spore or tip cultures and identified using ITS sequencing.

Fungal DNA extraction was done as described by Gat et al. (2012), as follows. Squares $\left(0.5 \mathrm{~cm}^{2}\right)$ from 7-day-old, single-spore mycelial cultures grown on PDA at $25^{\circ} \mathrm{C}$ were cut with a sterile scalpel and the agar was scraped from the bottom of each piece to exclude as much agar as possible. The pieces were homogenized in liquid nitrogen using a mortar and pestle. DNA was then extracted using the GenElute Plant Genomic DNA Miniprep Kit (Sigma) according to the manufacturer's instructions.
Molecular identification of the fungi was done by sequencing of the internal transcribed spacer (ITS) region using primers ITS1 (TCCGTAGGTGAACCTGCGG) and ITS4 (TCCTCCGCTTATT GATATGC) (White et al. 1990). Amplifications were done in a $25 \mu \mathrm{l}$ reaction mix containing 10 to $20 \mathrm{ng}$ of DNA, $1 \mu \mathrm{l}(10 \mu \mathrm{M})$ of each primer, dNTPs (2.5 mM each), $2.5 \mu l$ of reaction buffer, $0.125 \mu \mathrm{l}(0.625 \mathrm{U})$ of DreamTaq DNA polymerase (Fermentas, Lithuania), and PCR grade $\mathrm{ddH}_{2} \mathrm{O}$ (Fisher Scientific). Amplifications were performed in a Biometra Personal Cycler.

The PCR program for ITS was as follows: $96^{\circ} \mathrm{C}$ for $5 \mathrm{~min}$; followed by 35 cycles of $96^{\circ} \mathrm{C}$ for $45 \mathrm{~s}, 55^{\circ} \mathrm{C}$ for $45 \mathrm{~s}$, and $72^{\circ} \mathrm{C}$ for $1 \mathrm{~min}$; and then $72^{\circ} \mathrm{C}$ for $5 \mathrm{~min}$. PCR products were examined by electrophoresis in a $1.2 \%$ agarose gel (Sambrook et al. 1989). The PCR products of ITS were purified using DNA Clean \& Concentrator-5 purification kit (Zymo Research, U.S.A.) according to the manufacturer's instructions. Purified products were sent for direct PCR sequencing (Macrogen, Netherlands). Sequences of ITS relevant to this study were submitted to GenBank.

The significance of gummosis syndrome on tree and fruit development and on crop value. The dynamics of fruit growth were recorded in 2014 and 2015 in a commercial peach orchard located in the coastal plan in a village named Kidron $\left(31^{\circ} 48^{\prime} 12^{\prime \prime} \mathrm{N} ; 34^{\circ} 48^{\prime}\right.$ $12^{\prime \prime} \mathrm{E}$ ). The trees (cv. Oded, grafted on 677 rootstock) were planted in 2003, spaced $2.5 \mathrm{~m}$ apart within rows and $5 \mathrm{~m}$ between rows; trees were shaped in Palmette training system, irrigated via drip irrigation, and maintained, in respect to pruning, irrigation, fertilization, etc., according to the practices common in that area. According to the grower, the phytosanitary situation of the orchard was adequate in the first years, but as time passed, he occasionally noticed secretion of gum from a few scattered trees in the orchard. In summer 2013, immense fresh gum secretion was observed in 10 to $20 \%$ of the trees (Fig. 1A) and irregular necrosis of the xylem was observed in cuts made on gum-secreting limbs (Fig. 1B). In February 2014, when the trees were blooming, five trees exhibiting abundant gum secretion from the trunk and main limbs (Fig. 1C), bearing fruiting bodies of wood decaying (rot) fungi on their limbs (Fig. 1D), were marked with colored plastic stripes. These trees will be referred hereafter as "the symptomatic trees." At the same time, five adjacent trees having comparable dimensions (in respect to their height, canopy volume, blooming quantity, etc.) but without these symptoms were marked as well; these trees will be referred hereafter as "the asymptomatic trees." All marked trees grew in two rows at distance of $20 \mathrm{~m}$ between the farthest ones. The same trees were inspected in 2014 and 2015.

The development of the marked trees and the growth of fruits developing in these trees were recorded in the coming springs and early summers. Starting from early or mid-March (in 2014 and 2015, respectively), the diameter of 25 fruits per tree was measured weekly using a digital caliper (Mitutoyo, Japan). Measurements were performed by the same individual until commercial harvest (end of May). Sampled fruits were selected randomly; individual fruits were not marked and at each sampling, new fruits were measured. Three times each year, fruits at different sizes were harvested and brought to the laboratory. The diameter of each fruit (in $\mathrm{mm}$ ) was measured by using the digital caliper and its weight (in g) was determined. The relationship between fruit diameter and fruit weight was then determined using nonlinear regression analysis (Fig. 2). The dependent variable in the analysis was fruit weight $(\mathrm{g})$ and the independent variable was fruit diameter (mm). Results of the two seasons were pooled before analysis. This relationship was used to convert the seasonlong fruit diameter measurements to fruit weight. The calculated weight of fruits developing on symptomatic trees was then compared with that of fruits developing on asymptomatic trees. Differences in the weight of fruits developing on symptomatic or asymptomatic trees were examined using a two tail $t$ test.

In Israel, crop value is delineated based on the size category of the fruits. In summer 2014, the values of fruits matching size category $\leq 5$ (fruit diameter of $55 \mathrm{~mm}$ or less) was 2 new Israeli shekels (NIS) per kg; the values of fruits matching size category 6 (diameter of 55 to $60 \mathrm{~mm}$ ) was $4.25 \mathrm{NIS} / \mathrm{kg}$; for size category 6.5 it was 5.25 NIS/kg; for size category 7 it was $6.25 \mathrm{NIS} / \mathrm{kg}$; and for size category 
$\geq 7.5$ it was 6.75 NIS/kg. The exchange rate in May 2014 was US $\$ 1=3.46$ NIS. Data recorded in the last measurement (which was performed alongside commercial harvesting) were used to calculate the frequency distribution of fruit size category of fruits sampled from symptomatic and asymptomatic trees. Differences in the distributions of the fruits developing on symptomatic or asymptomatic trees were examined using the $\chi^{2}$ test. Then, the frequency distribution of the fruits sampled from asymptomatic trees was used to estimate crop value of a hypothetical orchard at which all trees were asymptomatic. Similarly, the frequency distribution of fruits sampled from symptomatic trees was used to estimate the crop value of a hypothetical orchard where all trees were symptomatic. Difference in crop value between the two hypothetical orchards, expressed in percentages, is an estimate for the financial loss imposed by gummosis syndrome due to the inferior quality of the fruits developing in orchards where the syndrome is widespread. Using the relationship between fruit diameter and fruit weight, the same procedure was used to estimate the financial loss imposed by gummosis syndrome due to the reduction in yield quantity in orchards where the syndrome is widespread. Adding the financial loss estimates related to fruit quality and yield quantity is an estimate for the total financial losses induced by the gummosis syndrome. Assuming the losses are relative to the incidence of symptomatic trees, we then estimated the expected losses imposed in hypothetical orchards with incidences of symptomatic trees ranging from $0 \%$ (all trees are asymptomatic) to $100 \%$ (all trees are symptomatic).

\section{Results}

The fungi associated with the gummosis syndrome of deciduous trees in Israel. Fungal isolation from necrotic tissues resulted in three main morphotypes. The first were white colonies with aerial mycelium that became gray to black within 5 to 7 days. The mycelia were branched and septate; dark brown to black pycnidia were formed on 20- to 30-day-old pure cultures. When prevailed, conidia were two-celled and thick-walled with oval shaped longitudinal striations. These colonies were morphologically identified as belonging to the Botryosphaeriaceae family. PCR amplification of the ITS ribosomal DNA of a single spore colony was sequenced and compered to NCBI GenBank (https://blast.ncbi.nlm.nih.gov/). A 99\% identity was found to Lasiodiplodia theobromae (KM278119). The second, a dark gray to black, wooly like mycelium, fast growing on PDA at $25^{\circ} \mathrm{C}$ for 5 days. The mycelia were branched and septated (4 to $8 \mu \mathrm{m}$ wide). Arthroconidia, dark brown, thick walled, one cell, 6.3 to $14.2 \times 2.0$ to $4.5 \mu \mathrm{m}$, ovate to rectangular cells were formed 5 to 7 days from inoculation. Based on these characteristics, the fungus was identified as Neoscytalidium dimidiatum (Penz.) Crous \&

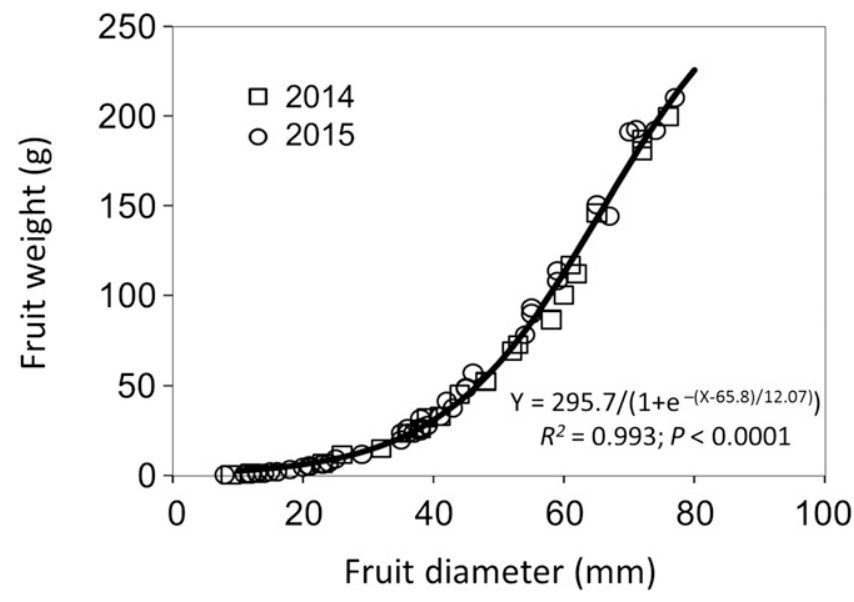

Fig. 2. The coincidence between fruit diameter and fruit weight as determined in fruits sampled in 2014 (open squares) and 2015 (open circles) from the studied peach orchard in Kidron.
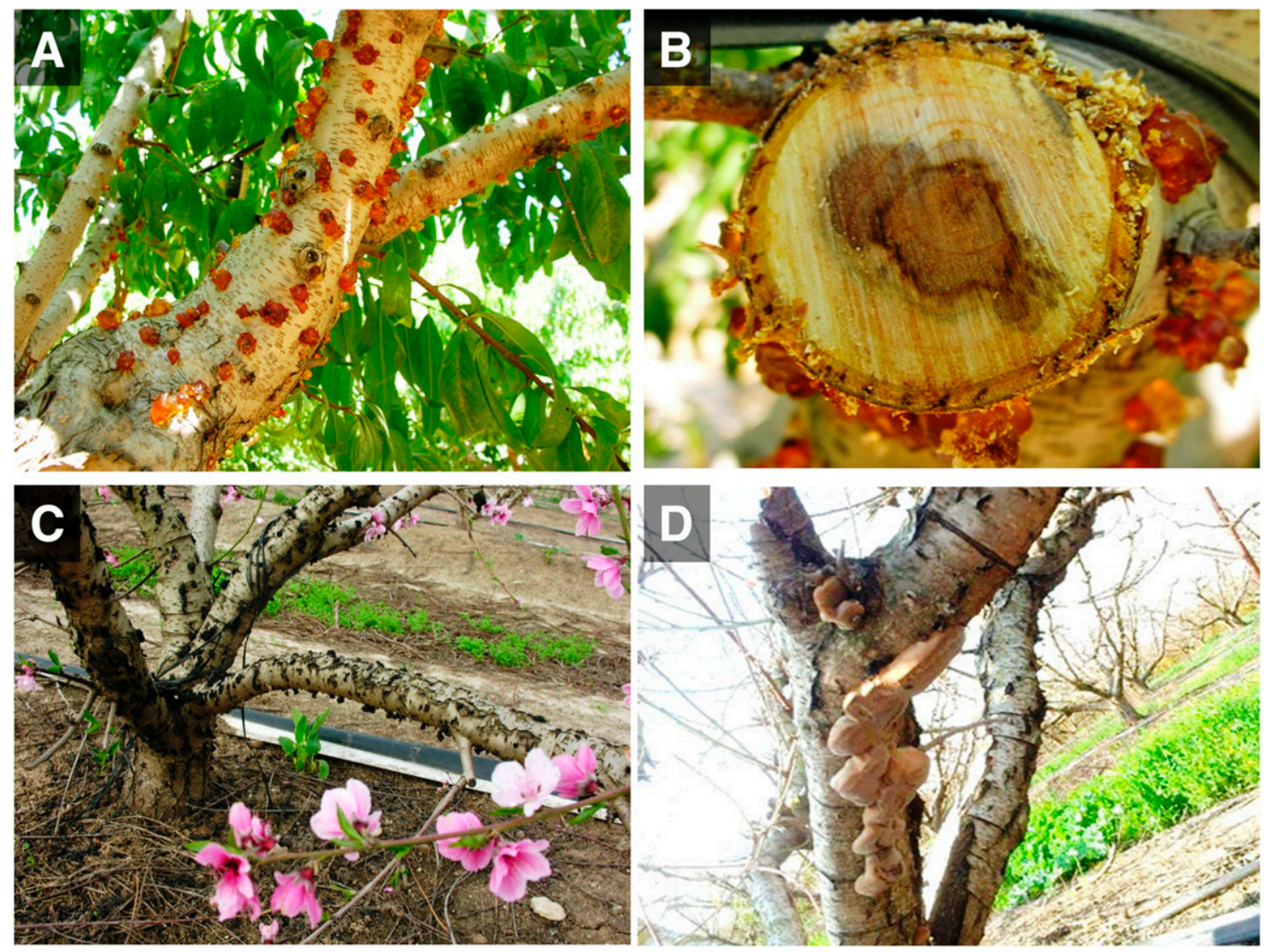

Fig. 1. Symptoms developing on symptomatic peach trees in Kidron in summer 2013: immense fresh gum secretion from the trunk and main limbs (A) and necrosis of the xylem in cuts made on gum-secreting limb (B). Symptoms observed on these trees in early spring 2014, during flowering: darkened gum secretion (C) and fruiting bodies of wood decaying (rot) fungi (D) 
Slippers, which belongs to the Botryosphaeriaceae family. PCR amplification of the ITS ribosomal DNA of a single spore colony was sequenced and compered to GenBank. A 98 to $100 \%$ identity was found to $N$. dimidiatum (KP132486, KR072527). The third had thick, cottony white mycelium with ochre pigmentation in the center of the colony. In some cases, small oozing structures were formed in the center of the culture. The hyphae had simple septa and branches. No spores were observed. PCR amplification of the ITS ribosomal DNA of a pure colony was sequenced and compered to GenBank. A 96 to $99 \%$ identity was found to Phellinus spp. (AY189704, AF250929, KU139144).

Sequences of ITS relevant to this study were submitted to GenBank and deposited as accession numbers KU957982-84 for L. theobromae, KY379224-29 for N. dimidiatum, and KU863540-42 for Phelinus sp. The sequences obtained in this study were compared with those already present in the GenBank database using BLAST.

Analysis of the isolation data revealed that fungi belonging to the Botryosphaeriaceae family were recorded from all sampling sites. In 13 out of the 29 (44.8\%), sole fungi were isolated from the symptomatic tissues and in the others, 2 or 3 fungal species had colonized the necrotic tissues. Botryosphaeria sp. was solely isolated from 8 out of the 15 orchards $(53.3 \%)$ from which it was recorded, L. theobromae in 2 out of $11(18.2 \%)$, and $N$. dimidiatum in 3 out of the 8 orchards $(37.5 \%)$ from which this fungus was recorded. Phellinus sp. was isolated from 16 of the 29 orchards $(53.3 \%)$, but in all cases it accompanied one of the other Botryosphaeriaceae fungi (Table 1). We could not find any obvious compatibility between the species of the isolated fungi and the species of the host.

The significance of gummosis syndrome on tree and fruit development and on crop value. Differences in the number of fruitlets developing on symptomatic and asymptomatic trees were minute, as the growers had thinned the surplus flowers, keeping the number of flowers remaining in each tree appropriate to its size and vigor. However, there was a large difference between symptomatic and asymptomatic trees in shoot growth and amount of foliage. While asymptomatic trees exhibited dense shoot growth and thick foliage (Fig. 3A and C), symptomatic trees were thin and had far fewer leaves on the boughs (Fig. 3B and D). When limbs of symptomatic trees were cut or when cores were drilled out from the trunks of these trees, necrosis could be observed on the xylem and phloem of the cuts and cores. Necrosis was expressed as browning and death of the phloem and browning of the xylem. The xylem and phloem of the cuts and cores made in asymptomatic trees were undamaged (Fig. 3E and F).

Measurements of fruit diameter were converted to fruit weight using the regression equation presented in Figure 2. Until the stone hardening stage of the fruits, the weight of fruits developing on symptomatic trees was, in most assessment dates, higher than the weight of fruits developing on asymptomatic trees. However, these differences were significant in only two assessment dates in 2015 . Following the termination of stone hardening stage of the fruits, the situation reversed and the rate of weight accumulation of fruits developing on symptomatic trees $(3.1 \pm 0.13$ and $3.44 \pm 0.14 \mathrm{~g} /$ day in 2014 and 2015, respectively) was lower than the rate of weight accumulation of fruits developing on asymptomatic trees $(4.5 \pm 0.21$ and $4.0 \pm 0.12 \mathrm{~g} /$ day in 2014 and 2015 , respectively).

At the time of commercial harvest, the average weight of fruits developing on symptomatic trees was significantly lower than the weight of fruits developing on asymptomatic trees. In 2014 and 2015, weights of the former were 125.1 and $132.7 \mathrm{~g}$ and weights of the latter were 160.1 and $150.1 \mathrm{~g}$ (22.3 and $11.5 \%$ difference), respectively (Fig. 4). In addition, there were marked differences in the frequency distribution of the diameter of the fruits developing on symptomatic and asymptomatic trees (Fig. 5). In 2014 and 2015, for example, 28.3 and $53.3 \%$ of the fruits developing on

Table 1. Details of the commercial orchards from which symptomatic and asymptomatic branches were sampled during $2012-15$ for isolation of fungi associated with the gummosis syndrome of deciduous fruit trees

\begin{tabular}{|c|c|c|c|c|}
\hline \multirow[b]{2}{*}{ Host species } & \multirow[b]{2}{*}{ Year } & \multicolumn{2}{|c|}{ Site of sampling } & \multirow[b]{2}{*}{ Isolated fungi } \\
\hline & & Village & Region $^{a}$ & \\
\hline \multirow[t]{6}{*}{ Apricot } & 2012 & Rosh Pina & Hula valley $(\mathrm{N})$ & Botryosphaeria sp.; L. theobromae; Phellinus sp. \\
\hline & 2012 & Cerem Maharal & Seashore plain $(\mathrm{N})$ & L. theobromae \\
\hline & 2012 & Furadis & Seashore plain $(\mathrm{N})$ & N. dimidiatum; Phellinus sp. \\
\hline & 2012 & Zikhron Ya'acove & Seashore plain $(\mathrm{N})$ & Botryosphaeria sp. \\
\hline & 2012 & Malkiah & Galilee mountains $(\mathrm{N})$ & L. theobromae; Phellinus sp. \\
\hline & 2013 & Neot Semadar & Central Negev (S) & Botryosphaeria sp. \\
\hline \multirow[t]{14}{*}{ Peach } & 2012 & Rosh Pina & Hula valley $(\mathrm{N})$ & Botryosphaeria sp.; L. theobromae; Phellinus sp. \\
\hline & 2012 & Givat Ada & Seashore plain $(N)$ & Botryosphaeria sp.; Phellinus sp. \\
\hline & 2012 & Bitzaron & Inner plains $(C)$ & L. theobromae; Phellinus sp. \\
\hline & 2012 & Kidron & Inner plains $(\mathrm{C})$ & N. dimidiatum; Phellinus sp. \\
\hline & 2012 & Kidron & Inner plains $(\mathrm{C})$ & N. dimidiatum; Phellinus sp. \\
\hline & 2012 & Carmel & Judea mountains (S) & N. dimidiatum \\
\hline & 2013 & Alma & Galilee mountains $(\mathrm{N})$ & Botryosphaeria sp.; Phellinus sp. \\
\hline & 2013 & Moshav Mazor & Seashore plain $(C)$ & Botryosphaeria sp. \\
\hline & 2013 & Bitzaron & Inner plains $(\mathrm{C})$ & Diplodia seriata; L. theobromae; Phellinus sp. \\
\hline & 2014 & Kidron & Inner plains $(\mathrm{C})$ & N. dimidiatum; L. theobromae; Phellinus sp. \\
\hline & 2014 & Azrikam & Inner plains $(\mathrm{C})$ & Botryosphaeria sp. \\
\hline & 2014 & Arugot & Inner plains $(\mathrm{C})$ & Botryosphaeria sp. \\
\hline & 2015 & Yesud HaMa'ala & Hula valley $(\mathrm{N})$ & Botryosphaeria sp. \\
\hline & 2015 & Misgav Dov & Inner plains $(\mathrm{C})$ & Botryosphaeria sp. \\
\hline \multirow[t]{6}{*}{ Nectarine } & 2012 & Ein Iron & Galilee mountains $(\mathrm{N})$ & L. theobromae \\
\hline & 2012 & Kfar Akhim & Inner plains $(C)$ & N. dimidiatum \\
\hline & 2012 & Tifrakh & Northern Negev (S) & Botryosphaeria sp.; Phellinus sp. \\
\hline & 2012 & Carmel & Judea mountains (S) & Botryosphaeria sp. \\
\hline & 2013 & Alma & Galilee mountains $(\mathrm{N})$ & Botryosphaeria sp.; Phellinus sp. \\
\hline & 2014 & Kidron & Inner plains $(\mathrm{C})$ & N. dimidiatum; L. theobromae; Phellinus sp. \\
\hline Plum & 2012 & Rosh Pina & Hula valley $(\mathrm{N})$ & Botryosphaeria sp; L. theobromae; Phellinus sp. \\
\hline Cherry & 2012 & Carmel & Judea mountains (S) & N. dimidiatum \\
\hline Almond & 2013 & Zikhron Ya'acove & Seashore plain $(\mathrm{N})$ & L. theobromae; Phellinus sp. \\
\hline
\end{tabular}

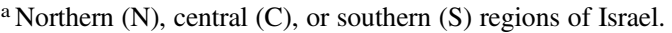



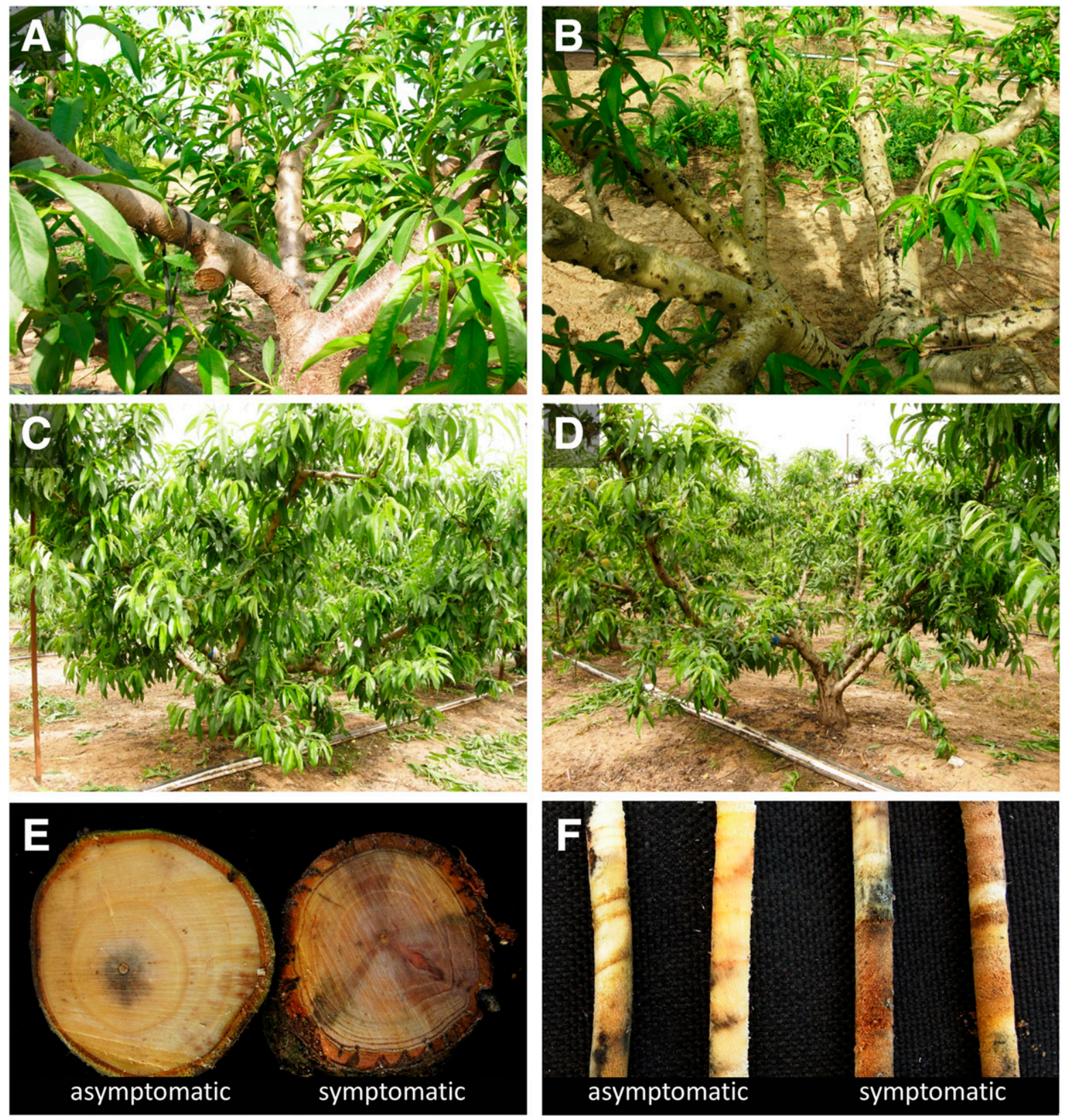

Fig. 3. Development of asymptomatic ( $\mathbf{A}$ and $\mathbf{C}$ ) and symptomatic ( $\mathbf{B}$ and $\mathbf{D})$ trees growing side by side in the studied peach orchard of Kidron in 2014. (E and $\mathbf{F})$ Cuts of limbs and cores drilled out from asymptomatic and symptomatic trees.

A

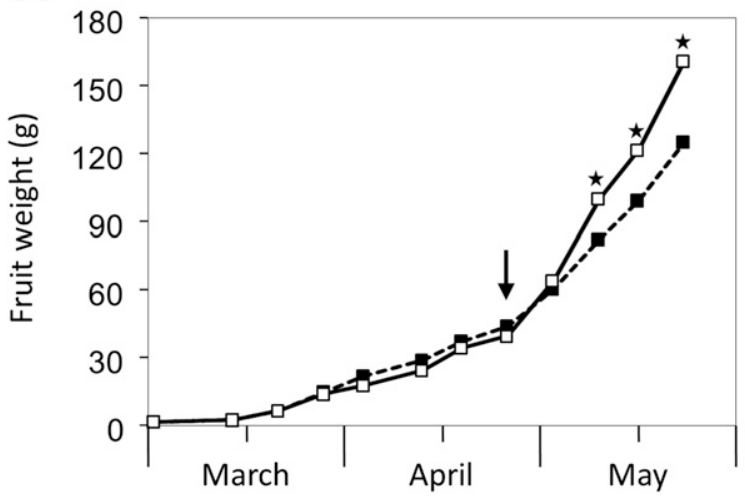

B

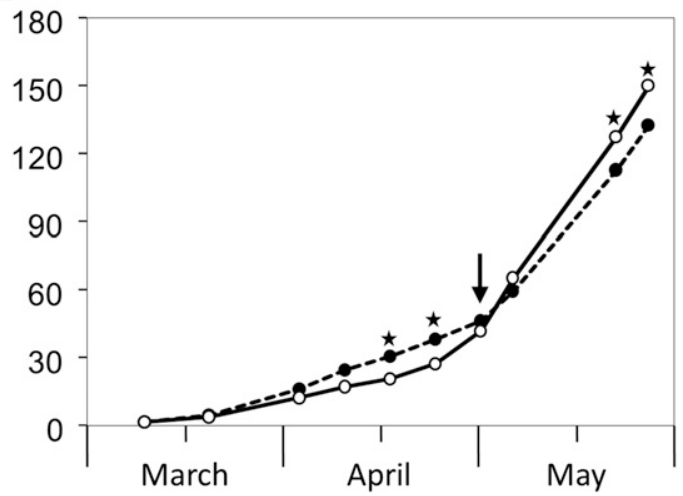

Fig. 4. The dynamics of fruit growth of fruits developing on symptomatic (filled symbols, dashed lines) and asymptomatic (open symbols, straight lines) peach trees in 2014 (A) and 2015 (B) in Kidron. Stars indicate significant differences $(P>0.05)$ in fruit weight at a certain assessment date as determined according to two-tail $t$ test. Arrows indicate the termination of stone hardening stage. 
symptomatic trees were at size category 6.5 (fruit diameter of 65 to $70 \mathrm{~mm}$ ) or above compared with 63.3 and $73.3 \%$ of the fruits developing on asymptomatic trees, respectively. These differences were highly significant $\left(P<0.001\right.$, as determined using the $\chi^{2}$ test $)$ in both years.

Crop value is constituted by the quantity of the yield (determined by fruit weight) and its quality (ascertained by fruit size). In 2014, the financial loss of crop developing on symptomatic trees was $41.9 \%$ and in 2015 it was $26.2 \%$. Of that, 22.5 and $11.5 \%$ resulted from reduction in yield quantity and 19.4 and $14.7 \%$ resulted from reduction in yield quality in 2014 and 2015, respectively. As not all trees in an orchard exhibit the gummosis syndrome, the actual loss is a function of the incidence of symptomatic trees (Fig. 6).

\section{Discussion}

The current study focuses on the third phase of the gummosis syndrome of deciduous trees (5-7 to 10-14 years after planting). Although symptoms are frequently observed at this phase in commercial orchards, not much is known about causal agents of the symptoms, the etiology of the disease, and its impact on crop productivity (Sharma and Gautam 1999). Growers in Israel (S. Antman, personal communication) and other places (Beckman et al. 2003) regard their orchards as undamaged and believe that the attainable yields are reached. In respect to the causal agent, results of the current study (Table 1) corroborated previous reports (Damm et al. 2007; Li et al. 1995, 2014; Ogawa et al. 1995; Weaver 1974): in all cases, fungi associated with the Botryosphaeriaceae family were isolated from tissues exhibiting typical gummosis symptoms. Wood decay fungi, in our case Phellinus sp., were also isolated from necrotic tissues (Table 1; Adaskaveg et al. 1993; Chen et al. 2015). Nevertheless, to the best of our knowledge, Koch's postulates have not been completed by these authors on mature trees and thus, the isolation of these fungi does not prove that they induced the symptoms. Koch's postulates were not completed on mature trees probably because the relatively long duration needed for expression of visible disease symptoms. In a parallel study, we have successfully completed Koch's postulates for L. theobromae, Botryosphaeria sp., $N$. dimidiatum, and Phellinus sp. on various deciduous fruit tree species. In these experiments, 1- to 2-year-old apricot and nectarine trees were artificially inoculated by one or both fungi and the typical disease symptoms were observed about 2 years later. These observations support the presumption that a complex of fungi are involved in the syndrome developing on mature trees.

If the assumption that fungi associated with the Botryosphaeriaceae family and the wood decay fungi are the causal agents of the gummosis syndrome in mature trees is acceptable, then several questions may arise: what were the sources of initial inoculum? What is the role of the fungi associated with the Botryosphaeriaceae family and what is the role of the wood decay fungi? When did infection occur? Unfortunately, not much is known about the etiology of the disease and experimental data, in general, are lacking. In these respects, there are two possible scenarios. According to the first scenario, the occurrence of the gummosis syndrome on mature trees (phases 3 and 4 of the syndrome) is not related to the occurrence of the syndrome on young trees (phase 1 of the syndrome) and they are denoted to two separated events. According to this scenario, healthy mature trees
A

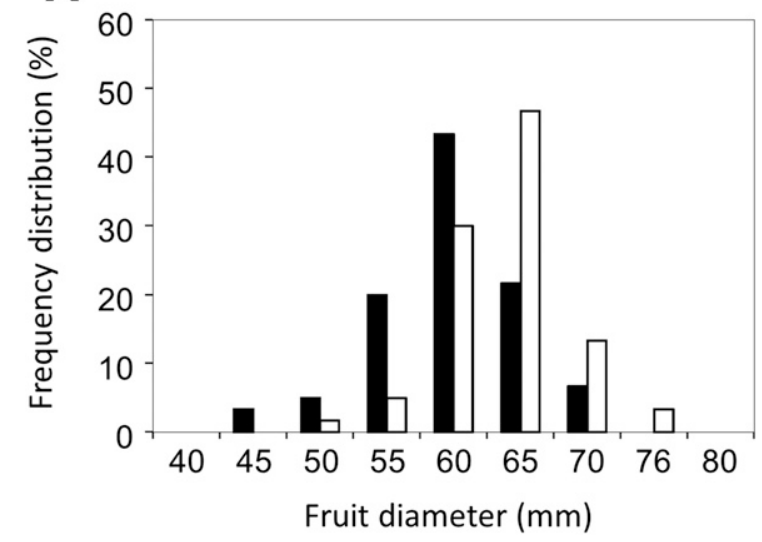

B

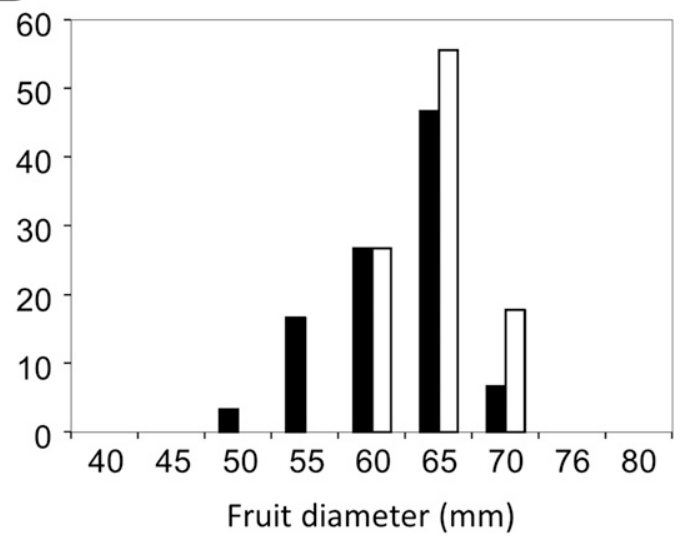

Fig. 5. Frequency distribution of the diameter of fruits developing on symptomatic (filled bars) and asymptomatic (open bars) peach trees in 2014 (A) and 2015 (B) in the studied orchard in Kidron. Measurements were performed at harvest.

A

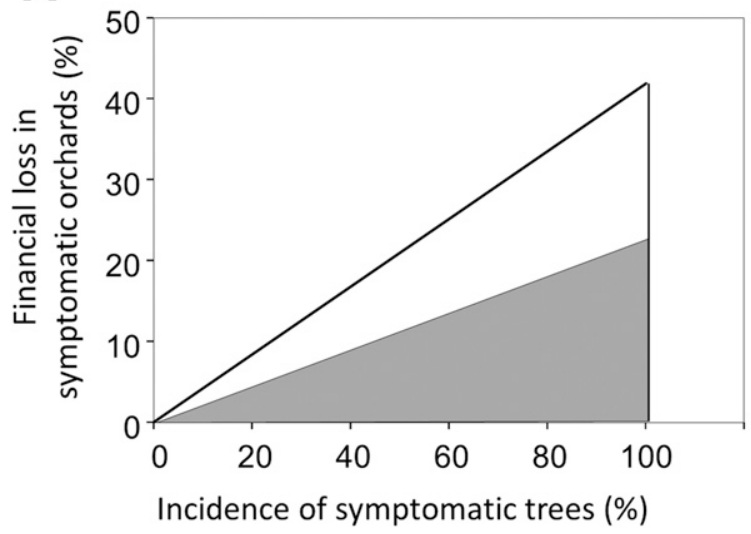

B

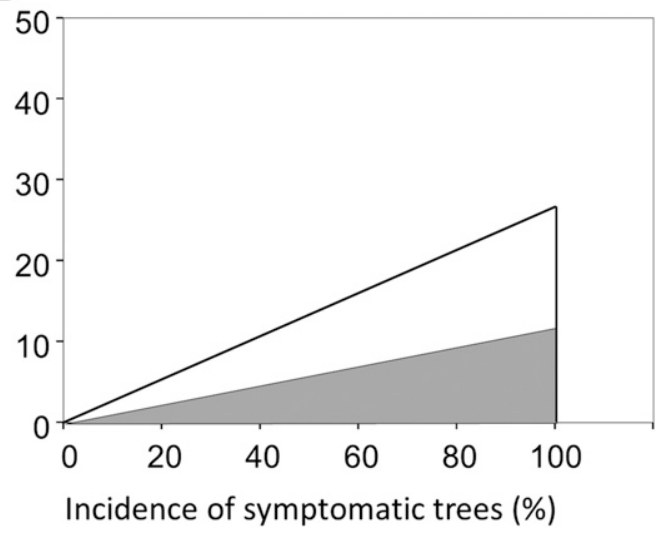

Fig. 6. Financial loss in peach orchards exhibiting the gummosis syndrome as a function of the incidence of symptomatic trees in the orchard. Loss results from the decrease in yield quantity per unit area (gray area) and the reduction in yield quality (open area). Estimations are based on data recorded in 2014 (A) and 2015 (B) in the studied orchard in Kidron. 
are infected by pathogenic fungi associated with the Botryosphaeriaceae family together with, before, or after the infection by the wood decay fungi. Inoculum of both fungi species is originated from external sources (for example, adjacent orchards and forests) and the fungi invade the trees through the root system, natural wounds, or cuts made during pruning (Edman et al. 2004; Gilbertson 1980; Michailides 1991; Ogawa et al. 1995; Pusey et al. 1986; Weaver 1974). As time passes, symptoms are observed on lateral branches, then on main limbs exemplifying the typical die-back sequence, and eventually on the whole trees. If this scenario is valid, then management efforts should be devoted to protecting the mature trees from infection and removing the symptomatic tissues to prevent pathogen progression from the exterior to the interior sections of the trees.

According to the second scenario, the occurrence of the gummosis syndrome on mature trees (phases 3 and 4 of the syndrome) is a continuation of syndrome occurring on young trees (phase 1 of the syndrome). In that case, the etiology of the syndrome is as follows. Fungi associated with the Botryosphaeriaceae family colonize the propagation material (rootstock and/or scions) while they are still attached to the mother trees (Waite et al. 2015). Seedlings produced from contaminated propagation material exhibit symptoms early and some of them wilt and die in the nursery. Other seedlings sustain the nursery stage and transplanted in commercial orchards. Some of the young trees exhibit gummosis symptoms in the first years after planting and they wilt and die. This is the first phase of the gummosis syndrome. However, a portion of the colonized young trees survive, overcome the infection, and continue to grow, presumably healthy. This is the second phase of the gummosis syndrome, which may extend up to 5 to 7 years after planting. Then, symptoms start to appear on these mature trees, in most cases after they were exposed to stress conditions such as severe drought, insect attack, severe pruning, or extreme weather conditions (Smith et al. 1994). According to this scenario, symptoms are observed first on the interior sections of the trees (trunks and main limbs) and not on the external sections, as the source of inoculum is originated from internal sources (the propagation material). Wood decay fungi invade the weakened trees through natural wounds or cuts made during pruning and intensify the development of the symptoms (Edman et al. 2004). If the second scenario is valid, then management efforts should be devoted to using healthy propagation material. Should this be done, infection of seedlings will be prevented and the subsequent development of the syndrome on young trees (phase 1) and on mature trees (phases 3 and 4) will be precluded. Even so, it needs to be mentioned that the scenarios are not mutually exclusive.

Several lines of evidence support the second scenario. First, the phytosanitary situation of the trees had a marked impact on shoot development and on fruit growth. Shoot growth, amount of foliage, and size of the fruits in symptomatic trees were markedly reduced compared with asymptomatic trees (Figs. 3 and 4). Second, in most cases, wilting and dying is initiated on the main limbs and the typical dieback sequence symptom is rare. Furthermore, in symptomatic trees, abundant gum is secreted from the trunk and main limbs (Fig. 1) and necrosis could be observed on the xylem and phloem of cores drilled out from the trunks of symptomatic trees and on cuts made in symptomatic limbs (Fig. 3E and F). Finally, when symptomatic trees were cut in slices, it was found that necrosis was more extensive in the slices made in trunks and main limbs and gradually restrained in slices made in the upper parts of the limbs. Often, the xylem and phloem of lateral branches appeared asymptomatic (results not shown). These observations support the hypothesis that the fungi inducing the gummosis syndrome invade the trees at early stages of their growth. Nevertheless, these are only circumstantial evidence and experimental data are needed to approve or reject the hypothesis that the development of gummosis in mature trees was originated at their nursery stages.

The decay fungus Phellinus sp. was isolated from 53.3\% of the samples. In all cases it accompanied one of the other Botryosphaeriaceae fungi (Table 1). This result was not unexpected as in most cases wood decay fungi invade hosts that are already weakened by other pathogens (Gilbertson 1980). Although they act as secondary pathogens, the role of wood decay fungi on the host plants may be devastating. In fact, most of the xylem necrosis observed in symptomatic peach trees in our study was presumably induced by Phellinus sp. rather than by the Botryosphaeriaceae fungi (Figs. 1 and 3). Furthermore, association of wood rotting fungi with pathogenic fungi forming disease complex is known in other pathosystems, such as Esca disease of vines (Lamichhane and Venturi 2015; Mundy and Manning 2010). Further insights into the infection biology and the role of Phellinus spp. in the gummosis syndrome of deciduous fruit trees are needed. These may be obtained by using previously developed methods and taxon-specific markers (Guglielmo et al. 2007, 2008).

The phytosanitary situation of the trees had a marked impact on fruit development. Until the termination of the stone hardening stage, the size of fruits developing on symptomatic trees was comparable, and in two sampling dates it was larger, then the size of fruits developing on asymptomatic trees (Fig. 4). These results were not expected and may be attributed to the competition for resources existing between vegetative and reproductive organs (shoot growth and developing fruits, respectively) (Bazzaz et al. 1987; Heuvel and DeMoranville 2009). In early spring, vegetative and reproductive growths occur concurrently and both are nourished by resources stored in the roots, trunks, and main limbs of the trees. The vascular systems of symptomatic trees are restricted by necrosis and the stronger sink forces imposed by the developing fruits favor allocation of resources toward the reproductive organs. This induces restricted growth of the shoots of symptomatic trees and the fruits developing on these trees develop faster compared with fruits on asymptomatic trees. It should be noted that growers are advised to prune the growing shoots in mid-April to restrict their growth and favor carbohydrate allocation to the developing fruits. In a peculiar way, the negative effect of the gummosis syndrome is seemingly positive, as it promotes fruit growth. After the stone hardening stage, the thicker foliage of the asymptomatic trees better support fruit development on these trees. In our study, the rate of fruit weight accumulation in asymptomatic trees was increased by 45.1 and $16.3 \%$ (in 2014 and 2015, respectively) compared with the rate of fruit weight accumulation in symptomatic trees (Fig. 4).

Fruit quality and yield quantity in trees exhibiting the typical gummosis syndrome symptoms were inferior to those of nearby asymptomatic trees. As indicated in the Materials and Methods section, fruit growth was recorded on the same trees in two consecutive years. Nevertheless, the impact of the gummosis syndrome was markedly larger in 2014 than in 2015 (Figs. 4, 5, and 6). The reason is not fully understood and may be attributed to differences between the two seasons when fruit weight accumulation was at its peak. In May 2014, temperature exceeded $35^{\circ} \mathrm{C}$ in 7 days ( $42 \mathrm{~h}$ in total) whereas in May 2015, temperature exceeded $35^{\circ} \mathrm{C}$ in only 4 days $(28 \mathrm{~h}$ in total). Similarly, in May 2014 , there were 10 days ( $57 \mathrm{~h}$ in total) with relative humidity below $30 \%$ compared with 5 days ( $44 \mathrm{~h}$ in total) in 2015 . It is possible that the impact of the gummosis syndrome is governed by the intensity of the stress to which the trees are exposed. The hotter and drier conditions prevailing in May 2014 imposed a more significant stress on symptomatic trees compared with the mild conditions in May 2015.

In trees exhibiting the gummosis syndrome, fruit quality and yield quantity are markedly reduced. According to our estimations, yield in symptomatic trees was lower by 11.5 to $22.5 \%$ (Fig. 4) and value was reduced by 14.7 to $19.4 \%$ (Figs. 5 and 6) compared with asymptomatic trees in 2014 and 2015, respectively. These are substantial losses. Nevertheless, the grower of the orchard where this study was performed was not aware of the losses occurring in his orchard. Similarly, growers of deciduous fruit trees in Israel and in other places are not aware of the losses occurring in their orchards. In our opinion, growers are not aware of the occurrence of losses because the damage is not obvious in the third phase of the gummosis syndrome. During the fruit growth period, the symptomatic trees seem visually healthy (wilting branches are pruned in the winter) and the number of fruits they carry is comparable to the number of fruits on asymptomatic trees. As symptomatic trees are distributed randomly in the orchard, fruits harvested from symptomatic trees are pooled with fruits harvested from asymptomatic trees and those originated from the former are unrecognizable. The impact of the gummosis syndrome on fruit 
quality and yield quantity at the orchard level is related to the incidence of symptomatic trees in the orchard. In the studied orchard, for example, 10 to $20 \%$ of the trees were symptomatic and the financial loss imposed by the syndrome was 4.2 to $8.4 \%$ in 2014 and 2.6 to $5.3 \%$ in 2015 . Although these losses are significant, as yields normally fluctuate between years and controls are unavailable, losses imposed by the gummosis syndromes are not distinguishable at the third phase of the gummosis syndrome. The situation changes during the fourth phase of the gummosis syndrome, where wilting and dying of branches, limbs, and even entire trees prevail. These symptoms are clearly recognizable and attract the attention of the growers who, after some time, decide to uproot the infected orchard. The conclusion of the current study is that the gummosis syndrome of deciduous trees imposes significant, hence undistinguishable, losses during the third phase of the syndrome. It should be acknowledged that this estimate is based on data from one site and was evaluated on peach only. Therefore, further research is needed.

\section{Acknowledgments}

This work was financed by the Chief Scientist of The Ministry of Agriculture and Rural Development (MOARD) of Israel; grant number 132-1534-11. Contribution No. 536/13 from the Agricultural Research Organization, The Volcani Center, Reshon LeZion, Israel.

\section{Literature Cited}

Achilea, O., and Sztejnberg, A. 1976. A Gummosis disease on lemon trees caused by the fungus Hendersonula toruloidea Nat. [Studies in Israel]. Hassadeh, Israel.

Adaskaveg, J., Miller, R., and Gilbertson, R. L. 1993. Wood decay, lignicolous fungi, and decline of peach trees in South Carolina. Plant Dis. 77:707-711.

Bazzaz, F. A., Chiariello, N. R., Coley, P. D., and Pitelka, L. F. 1987. Allocating resources to reproduction and defense. Bioscience 37:58-67.

Beckman, T. G., Pusey, P. L., and Bertrand, P. F. 2003. Impact of fungal gummosis on peach trees. HortScience 38:1141-1143.

Chen, C. X., Bock, C. H., Hotchkiss, M. H., Garbelotto, M. M., and Cottrell, T. E. 2015. Observation and identification of wood decay fungi from the heartwood of peach tree limbs in central Georgia, USA. Eur. J. Plant Pathol. 143:11-23.

Damm, U., Crous, P. W., and Fourie, P. H. 2007. Botryosphaeriaceae as potential pathogens of Prunus species in South Africa, with descriptions of Diplodia africana and Lasiodiplodia plurivora sp. nov. Mycologia 99:664-680.

Edman, M., Gustafsson, M., Stenlid, J., Jonsson, B. G., and Ericson, L. 2004. Spore deposition of wood-decaying fungi: importance of landscape composition. Ecography 27:103-111.

Gat, T., Liarzi, O., Skovorodnikova, Y., and Ezra, D. 2012. Characterization of Alternaria alternata causing black spot disease of pomegranate in Israel using a molecular marker. Plant Dis. 96:1513-1518.

Gilbertson, R. L. 1980. Wood-rotting fungi of North America. Mycologia 72: $1-49$.

Guglielmo, F., Bergemann, S. E., Gonthier, P., Nicolotti, G., and Garbelotto, M. 2007. A multiplex PCR-based method for the detection and early identification of wood rotting fungi in standing trees. J. Appl. Microbiol. 103:1490-1507.
Guglielmo, F., Gonthier, P., Garbelotto, M., and Nicolotti, G. 2008. A PCR-based method for the identification of important wood rotting fungal taxa within Ganoderma, Inonotus s.1. and Phellinus s.l. FEMS Microbiol. Lett. 282:228-237.

Heuvel, J. E. V., and DeMoranville, C. J. 2009. Competition between vegetative and reproductive growth in cranberry. HortScience 44:322-327.

Jakoby, T., Ben Gal, O., and Sztejnberg, A. 1982. Hendersonula toruloidea the causal agent of branches wilt disease on Apricot in israel. Anotea 35:469-472 (In Hebrew).

Lamichhane, J. R., and Venturi, V. 2015. Synergisms between microbial pathogens in plant disease complexes: a growing trend. Front. Plant Sci. 6:385.

Li, H.-Y., Cao, R.-B., and Mu, Y.-T. 1995. In vitro inhibition of Botryosphaeria dothidea and Lasiodiplodia theobromae, and chemical control of gummosis disease of Japanese apricot and peach trees in Zhejiang Province, China. Crop Prot. 14:187-191.

Li, Z., Wang, Y.-T., Gao, L., Wang, F., Ye, J.-L., and Li, G.-H. 2014. Biochemical changes and defence responses during the development of peach gummosis caused by Lasiodiplodia theobromae. Eur. J. Plant Pathol. 138:195-207.

Michailides, T. J. 1991. Pathogenicity, distribution, sources of inoculum, and infection courts of Botryosphaeria dothidea on pistachio. Phytopathology 81:566-573.

Mundy, D., and Manning, M. 2010. Ecology and management of grapevine trunk diseases in New Zealand: a review. N. Z. Plant Prot. 63:160-166.

Nattrass, R. 1933. A new species of Hendersonula (H. toruloidea) on deciduous trees in Egypt. Trans. Br. Mycol. Soc. 18:189-198.

Ogawa, J. M., Zehr, E. I., Bird, G. W., Ritchie, D. F., Uriu, K., and Uyemoto, J. K., eds. 1995. Compendium of Stone Fruit Diseases. American Phytopathological Society, St. Paul, MN.

Pusey, P. L., Reilly, C. C., and Okie, W. R. 1986. Symptomatic responses of peach trees to various isolates of Botryosphaeria dothidea. Plant Dis. 70:568-572.

Rotem, Y., Ben-Gal, O., and Sztejnberg, A. 1991. The causal agents and prevention of gummosis diseases in apricots. Phytoparasitica 19:238-239.

Sambrook, J., Fritsch, E. F., and Maniatis, T. 1989. Molecular Cloning: A Laboratory Manual (2nd ed.). Cold Spring Harbor Laboratory Press, Cold Spring Harbor, NY.

Sessa, L., Abreo, E., Bettucci, L., and Lupo, S. 2016. Botryosphaeriaceae species associated with wood diseases of stone and pome fruits trees: symptoms and virulence across different hosts in Uruguay. Eur. J. Plant Pathol. 146:519-530.

Sharma, J., and Gautam, D. 1999. Gummosis complex in stone and nut fruits Pages 275-290 in: Diseases of Horticultural Crops-Fruits. L. R. Verma and R. C. Sharma, eds. Indus Publishing Co., New Delhi, India.

Slippers, B., Smit, W. A., Crous, P. W., Coutinho, T. A., Wingfield, B. D., and Wingfield, M. J. 2007. Taxonomy, phylogeny and identification of Botryosphaeriaceae associated with pome and stone fruit trees in South Africa and other regions of the world. Plant Pathol. 56:128-139.

Smith, H., Kemp, G., and Wingfield, M. J. 1994. Canker and die-back of Eucalyptus in South Africa caused by Botryosphaeria dothidea. Plant Pathol. 43:1031-1034.

Waite, H., Whitelaw-Weckert, M., and Torley, P. 2015. Grapevine propagation: principles and methods for the production of high-quality grapevine planting material. N. Z. J. Crop Hortic. Sci. 43:144-161.

Weaver, D. 1974. A gummosis disease of peach trees caused by Botryosphaeria dothidea. Phytopathology 64:1429-1432.

White, T. J., Bruns, T., Lee, S., and Taylor, J. W. 1990. Amplification and direct sequencing of fungal ribosomal RNA genes for phylogenetics. Pages 315-322 in: PCR Protocols: A Guide to Methods and Applications. M. A. Innis, D. H. Gelfand, J. J. Sninsky, and T. J. White, eds. Academic Press, San Diego. 